\title{
Fungal laccases and its importance
}

\section{Mousa MK}

Botany Department, Faculty of Science, Suez Canal University, Ismailia 41522, Egypt.

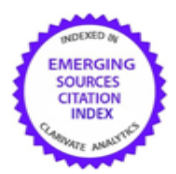

Published by Arab Society for Fungal Conservation

Laccase (benzenediol oxygen oxidoreductase, EC 1.10.3.2) is a highly unspecific enzyme containing up to 4 copper atoms within their catalytic sites (Duran and Esposito 2000). It catalyzes the oxidation of various phenolic compounds and aromatic amines with molecular oxygen as an electron acceptor. Laccase production has been reported in fungi such as; Botrytis cinerea, Pleurotus ostreatus, Pleurotus eryngii, Fusarium incarnatum, Aspergillus flavus, Chaetomium globosum, plants and bacteria.

Yoshida first described laccase in 1883 from the exudates of the Japanese lacquer tree, Rhus vernicifera. However, in 1896, for the first time, both Bertrand and Laborde demonstrated laccase to be a fungal enzyme. Some soil bacteria were also reported to produce extracellular laccase.

In fungi, laccases play a variety of physiological roles including morphogenesis, fungal plant pathogen/host interaction, stress defense, and lignin degradation. Due to its relatively broad substrate specificity, it has wide potential industrial applicability including pulp bleaching in the paper industry, dye decolorization, oxygen cathode development for biofuel cells, biosensors, bioremediation, and detoxification of environmental pollutants. Heap et al. (2014) used laccase in an enzymatic pretreatment method to improve lignocellulosic saccharification. Furthermore, laccases have medical applications in certain drugs preparations as anticancer and detox to minimize toxic cosmetics effects.

In view of the importance of laccases, the present study aimed to investigate laccase production by some microorganisms isolated from different habitats. More consideration was given to optimize cultural conditions for maximum laccase production by the most potent microorganism. Furthermore, the antitumor activity of the crude laccase extract was tested against some cancer cell lines.

Laccase plays important role in lignin biodegradation, but earlier its application was limited to phenolic compounds, because of low oxidation potential of such enzymes. Laccases are receiving much attention from researchers around the globe because of their specific nature. They have many industrial applications because of their innate ability of oxidation of a broad range of phenolic and non-phenolic compounds. The biotechnological significance of laccase enzymes has led to a drastic increase in the demand for these enzymes in the recent time.

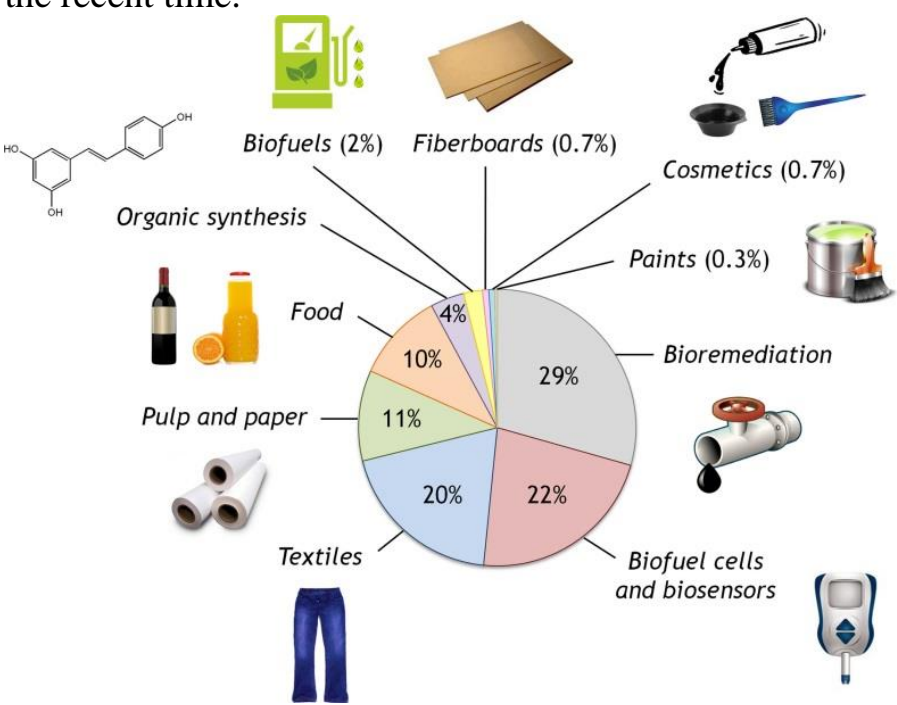

Breakdown of the biotechnological applications of laccases (Mate and Alcalde 2016).

Laccases are promising to replace the conventional chemical processes of several industries. The introduction of the laccase-mediator system provides a biological alternative to traditional chlorine bleaching processes. One of the limitations to the large-scale application of the 
enzyme is the lack of capacity to produce large volumes of highly active enzyme. These problems can be solved with the use of recombinant organisms or screening for natural hypersecretory strains.

Environmental factors influence the ability of fungi to produce high titers of laccase, and different strains react differently to these conditions. One should thus select a strain capable of producing high concentrations of a suitable enzyme and then optimize conditions for laccase production by the selected organism. The effective catalytic properties of enzymes have already promoted their introduction into several industrial products and processes. Recent developments in biotechnology, particularly in areas such as protein engineering and directed evolution, have provided important tools for the efficient development of new enzymes. This has resulted in the development of enzymes with improved properties for established technical applications and in the production of new tailor-made enzymes for entirely new areas of application where enzymes have not previously been used.

\title{
Further readings
}

Abdel-Azeem AM, Salem FM (2012) Biodiversity of laccase producing fungi in Egypt. Mycosphere 3(5): 900-920.

Couto SR, Herrera JLT (2006) Industrial and biotechnological applications of laccases: A review. Biotech Adv 24:500 -513 .

Duran N, Esposito E (2000) Potential applications of oxidative enzymes and phenoloxidase-like compounds in wastewater and soil treatment: a review: Appl Catal B Environ 28:83-99.

Giardina P, Faraco V, Pezzella C, Piscitelli A, Vanhulle S, Sannia G (2010) Laccases: a never-ending story. Cell Mol Life Sci 67:369-385.

Heap L, Green A, Brown D, Dongen B, Turner N (2014) Role of laccase as an enzymatic pretreatment method to improve lignocellulosic saccharification. Catal Sci Technol 4:2251-2259.

Levine, W. (1965) The Biochemistry of Copper, Academic Press Inc., New York, p. 371-385.

Madhavi V, Lele SS (2009) Laccase: properties and applications. Bioresour Technol 4(4):1694-1717.

Martins L, Soares C, Pereria M, Teixeira M, Costa T, Jones G and Henriques A (2002) Molecular and biochemical characterization of a highly stable bacterial laccase that occurs as a structural component of the Bacillus subtilis endospore coat. J Biol Chem 277:18849-18859.

Mayer A and Staples R (2002) Laccase: new functions for an old enzyme: Phytochem 60:551-65

Palmeri G, Bianco C, Cennamo G, Giardina P, Marino G, Monti M and Sannia G (1993) Purification, characterization, and functional role of a novel extracellular protease from Pleurotus ostreatus. Appl Environ Microbiol 67:2754 2759.

Thurston C (1994) The structure and function of fungal laccases. Microbiol 140:19-26.

\author{
ARTICLE INFO \\ Article history \\ Received 8 June 2020 \\ Received revised 19 June 2020 \\ Accepted 29 June 2020 \\ Available online 30 June 2020 \\ (C) Mousa 2020 \\ Corresponding Editor: \\ Darwish AMG, Abo Nahas HH
}

